\title{
Torn Between Caution and Compassion: a Dilemma for Clinicians from Black and Minority Ethnic Groups During the COVID-19 Pandemic
}

\author{
Nisa Shah ${ }^{1} \cdot$ Irfan M. Ahmed ${ }^{2} \cdot$ Tahir Nazir $^{2}$ \\ Received: 23 July 2020 / Revised: 30 November 2020 / Accepted: 1 December 2020 / Published online: 7 January 2021 \\ (C) W. Montague Cobb-NMA Health Institute 2021
}

\begin{abstract}
The wide disparity in coronavirus disease (COVID-19)-related death rates based upon the ethnic origin is well established by now. The higher incidence of COVID-19 deaths amongst the healthcare staff belonging to black and minority ethnic (BAME) communities living in the United Kingdom has generated a great deal of concern and anxiety in clinicians. Public Health England (PHE) has outlined mitigation strategies after immense pressure from professional organisations and influential clinical leaders. Although seemingly well thought through, these measures fall short of addressing the professional, moral and emotional dilemma faced by the BAME clinicians who feel that they are being expected to choose between their duty towards their patients and the profession, and their responsibility to look after their own health.
\end{abstract}

Keywords Ethnic minorities · COVID $19 \cdot$ Role modelling

\section{Introduction}

As clinicians from black and minority ethnic (BAME) background working in the acute services fighting the COVID-19 pandemic, we acknowledge that the contagion has led to disproportionately higher mortality rates in the ethnic minorities. The excess mortality from the SARS-Cov-2 virus in BAME groups is not limited to the general population; it has also adversely affected the healthcare professionals belonging to these backgrounds. Many governments (including the United Kingdom) have rolled our risk assessments and mitigation programmes for BAME healthcare workers with a view to identify those at the highest risk of developing severe disease and re-assign them to the nonacute areas. As clinicians, we find ourselves in a dilemma; whether to exercise caution and avoid high risk work environment or to follow our compassion and continue to deliver the best quality clinical care at the front end.

Tahir Nazir

Tahir.Nazir@lthtr.nhs.uk

Preston Clinical Commissioning Group, Preston, UK

2 Lancashire Teaching Hospitals NHS Foundation Trust, Royal Preston Hospital, Preston PR2 9HT, UK

\section{Ethnicity and COVID-19 Mortality}

Since the report of the first case of coronavirus disease (COVID19) in China late last year, the infection has rapidly spread around the globe in the last 9 months. To date, the total number of confirmed COVID-19 cases stands at 63 million with approximately 1.5 deaths across the world [1]. Advancing age, diabetes, hypertension and underlying respiratory and cardiovascular conditions are associated with an increased risk of developing severe form of the disease ultimately resulting in higher mortality rates [2]. In addition, individuals from black and minority ethnic (BAME) background are also at higher risk of death from COVID-19. The initial data from the Office of National Statistics (UK) revealed that after adjusting for age, sociodemographic characteristics and comorbidities; patients from BAME groups were nearly twice as likely to die from the pandemic compared to those belonging to the white ethnicity [3]. The UK ethnic minorities represent $14 \%$ of the population; however, approximately one-third of seriously ill intensive care COVID-19 patients belonged to BAME background [4]. Similar figures have been recorded in the USA, where 24.3\% of all COVID-related deaths occurred in black Americans who account for $12.4 \%$ of the USA population [5].

The ethnicity-related excess rates of COVID-19 deaths are not limited to the general population; similar trends have been 
noted in the healthcare professionals working for the National Health Service (NHS), too. According to the data published by British Medical Association (BMA), approximately onefifth of NHS healthcare workers come from black or ethnic minority background; however, two-thirds of all healthcare staff who died due to COVID19 were from these ethnic groups [6]. The mortality figures for medical staff are even more worrying, where $94 \%$ of all deaths occurred in doctors originating from black and minority ethnic groups [7]. The disproportionately high mortality rate amongst BAME staff is not adequately explained by the age, gender and sociodemographic factors and other work-place based inequalities faced by these staff groups must be explored further [8]. Fear of repercussions for reporting COVID related concerns, adverse psychological support, isolation at work place and poor access to personal protective equipment may all play a role.

\section{Stuck Between the Risk Mitigation and Role Modelling}

In line with BMA's recommendations, NHS organisations have started to carry out risk assessments for medical staff belonging to ethnic minorities. It was thought that a robust, well-structured and collaborated risk assessment would improve the confidence amongst the healthcare workers about on-the-job protection. Although 'remote working' was initially suggested as an option to reduce the exposure to contagion; however, it is not feasible for the majority of frontline staff who are involved in providing direct face-to-face care to acutely unwell patients. Besides, it is well documented that remote working facilities are not consistently available to all medical and nursing staff, with BAME staff being particularly disadvantaged [9]. Senior clinicians working in the emergency and acute medicine specialties were offered risk assessment with a view to redeploy those with the highest risk, away from the frontline acute areas. Whilst this strategy can help to reduce their risk of contracting COVID-19; it does not address their professional and emotional needs. Like our non-BAME colleagues, we also take our commitment to providing a timely, effective and compassionate clinical care to patients at the front door very seriously. Managing the COVID-19 pandemic is an unfinished task, and as senior clinicians and leaders, we would not just walk away from it, until it is successfully dealt with. Moreover, our responsibility is not limited to providing the direct patient care; we also have a duty to guide our teams comprising medical, nursing and allied healthcare staff, who are looking towards us for inspiration during these difficult times. Role modelling is an integral component of clinical teaching and is particularly effective during complicated and challenging situations. To 'lead by example' is what distinguishes clinical teachers from the classroom lecturers [10], and facilitates the development of attitudes, values and professional competencies in medical students and trainees. We find ourselves in a dilemma, stuck between our passion of medicine and duties as role models on one hand and personal health risks, on the other, whilst we are advised to exercise caution and accept re-deployment to non-acute areas to reduce the risk of developing severe COVID-19 disease. Guided by our professional and moral responsibility, we wish to continue leading our team from the front with compassion, courage and commitment during these difficult times.

\section{Conclusion}

As we write these lines, the world continues to battle the COVID-19 pandemic. It is a testing time for our communities and the medical profession. It is important that the risk assessments are open-ended and genuinely attempt to capture the sensitivity of the situation of BAME staff. Urgent steps must be taken to improve their access to PPE and to facilitate remote working, where appropriate. Whilst most of the risk assessment focus on the physical factors; employers must also nurture the psychological and emotional well-being of their BAME health care staff. The risk of severe COVID-19 disease and death remains high in the BAME healthcare staff. Despite this, as clinicians from minority ethnic groups, we feel reinfused with enthusiasm to continue serving our patients and profession. When this pandemic will be over, we would look back at this difficult era, with pride that not only we served our patients but also led our trainees in the face of adversity and uncertainty, during a raging pandemic.

Authors' Contributions NS conceptualised and wrote the original manuscript. IA conceptualised and edited the original manuscript. TN conceptualised and edited the original manuscript.

\section{Compliance with Ethical Standards}

Conflict of Interest The authors declare that they have no conflict of interest.

\section{References}

1. John Hopkins Coronavirus Resource Center. COVID-19 Map Johns Hopkins Coronavirus Resource Center [Internet]. COVID19 map. 2020. Available from: https://coronavirus.jhu.edu/map. $\mathrm{html}$

2. Du RH, Liang LR, Yang CQ, Wang W, Cao TZ, Li M, et al. Predictors of mortality for patients with COVID-19 pneumonia caused by SARSCoV- 2: a prospective cohort study. Eur Respir J. 2020;55(5):2000524.

3. Office for National Statistics (UK). Coronavirus-related deaths by ethnic group, England and Wales methodology - Office for National Statistics [Internet]. Coronavirus-related deaths by ethnic group, England and Wales. 2020 [cited 2020 Jun 18]. Available from: https://www.ons.gov.uk/peoplepopulationandcommunity/ 
birthsdeathsandmarriages/deaths/methodologies/coronavirus relateddeathsbyethnicgroupenglandandwalesmethodology.

4. Intensive Care National Audit and Research Centre. ICNARC reports [Internet]. INARC report on COVID-19 in critical care. 2020 [cited 2020 Jun 18]. Available from: https://www.icnarc. org/Our-Audit/Audits/Cmp/Reports.

5. APM Research Lab USA. COVID-19 deaths analyzed by race and ethnicity - APM Research Lab [Internet]. COVID-19: deaths analyzed by race and ethnicity. 2020 [cited 2020 Jun 18]. Available from: https://www.apmresearchlab.org/covid/deaths-by-race.

6. British Medical Association. COVID-19: the risk to BAME doctors [Internet]. COVID-19: the risk to BAME doctors. 2020 [cited 2020 Jun 18]. Available from: https://www.bma.org.uk/advice-andsupport/covid-19/your-health/covid-19-the-risk-to-bame-doctors.

7. Kirby T. Evidence mounts on the disproportionate effect of COVID-19 on ethnic minorities. Lancet Respir Med. 2020;8(6): 547-8.
8. NHS workforce equality standard: 2019 data analysis report for NHS trusts. Avaialble from: https://www.england.nhs.uk/wpcontent/uploads/2020/01/wres-2019-data-report.pdf.

9. British association of PHysicians of INdian Origin. BAPIOCOVID 19 survey of over 2000HCSw reveals BAME background is an independent risk factor. Available from: https://www.baio.co. uk.

10. Harden RM, Crosby J. AMEE guide no 20: the good teacher is more than a lecturer - the twelve roles of the teacher. Med Teach. 2000;22(4):334-47.

Publisher's Note Springer Nature remains neutral with regard to jurisdictional claims in published maps and institutional affiliations. 